\title{
CASE RECORDS OF THE MASSACHUSETTS GENERAL HOSPITAL:
}

\section{Case 30-2020: A 54-Year-Old Man with Sudden Cardiac Arrest}

Elazer R. Edelman, M.D., Ph.D., Neel M. Butala, M.D., M.B.A., Laura L. Avery, M.D., Andrew L. Lundquist, M.D., Ph.D., Anand S. Dighe, M.D., Ph.D.

Department of Medicine, Brigham and Women's Hospital (E.R.E.), the Departments of Medicine (N.M.B., A.L.L.), Radiology (L.L.A.), and Pathology (A.S.D.), Massachusetts General Hospital, and the Departments of Medicine (E.R.E., N.M.B., A.L.L.), Radiology (L.L.A.), and Pathology (A.S.D.), Harvard Medical School - all in Boston, and the Institute for Medical Engineering and Science, Massachusetts Institute of Technology, Cambridge (E.R.E.).

\section{Presentation of Case}

\section{Dr. Jacqueline B. Henson (Medicine):}

A 54-year-old man was evaluated at this hospital after cardiac arrest associated with ventricular fibrillation.

The patient had been in his usual state of health until midday on the day of admission, when he was in a fast-food restaurant and gasped suddenly, with full-body shaking and loss of consciousness. The shaking movements ceased quickly, but he remained unresponsive. Emergency medical services personnel arrived after approximately 4 minutes, and cardiopulmonary resuscitation (CPR) was initiated. The heart rhythm was identified as ventricular fibrillation; four shocks were delivered, and the patient received intravenous naloxone, amiodarone, and a bolus of epinephrine followed by a continuous infusion. A slow, wide-complex heart rhythm with a rate of 40 beats per minute was noted, reportedly with concurrent return of mental status, but CPR had to be resumed after pulselessness recurred.

The patient arrived at this hospital 30 minutes after the initial arrest. The patient was an unresponsive, middle-aged man who had undergone mechanical CPR and had no external signs of trauma. Empirical intravenous calcium chloride, dextrose and insulin, and sodium bicarbonate were administered. In addition, vasopressin, norepinephrine, rocuronium, and ketamine were administered intravenously, and aspirin was administered rectally. Emergency intubation of the trachea was performed, and an orogastric tube, a femoral arterial catheter, and a femoral central venous catheter were placed. 


\section{Dr. Neel M. Butala:}

An electrocardiogram (ECG) (Figure 1A) showed uncertain atrial activity; a regular accelerated idioventricular rhythm at a rate of 70 beats per minute, with a very wide QRS complex and multifocal premature ventricular contractions; possible elevations of the ST segment in leads aVR, aVL, and $\mathrm{V}_{1}$; and the presence of $\mathrm{U}$ waves.

\section{Dr. Henson:}

Initial laboratory test results obtained 25 minutes after the patient arrived at this hospital are shown in Table 1. Cardiac ultrasound images obtained at the bedside showed marked global left ventricular dysfunction. Spontaneous circulation was restored; the heart rate was 108 beats per minute and the blood pressure 139/92 $\mathrm{mm} \mathrm{Hg}$ while the patient was receiving intravenous epinephrine and norepinephrine. A repeat ECG (Figure 1B) showed findings similar to those seen on presentation.

The neurology service was consulted. A repeat examination, performed after the medications used for sedation were discontinued, revealed anisocoria and sluggishly reactive pupils (the left was $7 \mathrm{~mm}$ in diameter, and the right was $5 \mathrm{~mm}$ ); corneal reflexes and response to noxious stimuli were absent. Therapeutic hypothermia was not initiated.

\section{Dr. Laura L. Avery:}

Computed tomography of the head (Figure 1C), performed without the administration of intravenous contrast material, revealed preservation of differentiation between gray and white matter, without evidence of territorial infarct, intracranial hemorrhage, or mass lesions.

\section{Dr. Butala:}

The patient was transferred to the cardiac catheterization laboratory, where a transaortic percutaneous ventricular assist device was placed through the femoral artery, and thereafter, the patient was weaned from epinephrine and norepinephrine. Coronary angiography (Figure 1D and 1E) revealed only minimal luminal irregularities (see Videos 1 and 2, available with the full text of this article at NEJM.org). Subsequent catheterization of the right and left sides of the heart revealed a right atrial pressure of $13 \mathrm{~mm} \mathrm{Hg}$, a pulmonary capillary wedge pressure of $27 \mathrm{~mm} \mathrm{Hg}$, and a left ventricular end-diastolic pressure of $30 \mathrm{~mm} \mathrm{Hg}$. The pulmonary arterial oxygen saturation was $85 \%$.

\section{Dr. Henson:}

Additional laboratory test results returned during the catheterization procedure (Table 1) were notable for a blood potassium level of $2.0 \mathrm{mmol}$ per liter (normal range, 3.4 to 5.0). The patient received $60 \mathrm{mmol}$ of enteral potassium chloride and $80 \mathrm{mmol}$ of intravenous potassium chloride. Three hours after the patient arrived at this hospital, he was admitted to the cardiac intensive care unit (ICU), whereupon limited additional history was available from family and friends.

There was no history of chest pain, dyspnea, or symptoms of heart failure or dysrhythmia. $\mathrm{He}$ had a poor diet, consisting primarily of several packages of candy daily; 3 weeks earlier, 
he had switched the type of candy he was eating. He had no sick contacts, fever or chills, nausea, vomiting, or diarrhea.

Medical history included previous heroin use disorder and untreated hepatitis $\mathrm{C}$ virus infection. The patient had never had any adverse drug reactions. He worked in construction. He did not drink alcohol, he smoked one pack of cigarettes daily and had done so for 36 years, and he had reportedly been abstinent from opiates for the previous 3 years. There was no family history of cardiac, respiratory, renal, neurologic, or endocrine disease.

The temperature was $34.0^{\circ} \mathrm{C}$, the heart rate 119 beats per minute, the blood pressure $81 / 53$ $\mathrm{mm} \mathrm{Hg}$ (on the percutaneous ventricular assist device), and the oxygen saturation 95\% while the patient was receiving oxygen through a mechanical ventilator (fraction of inspired oxygen, 0.50 ; respiratory rate, 24 breaths per minute; positive end-expiratory pressure, $5 \mathrm{~cm}$ of water; tidal volume, $450 \mathrm{ml}$ ). On examination, he was unresponsive; the pupils remained sluggishly reactive and asymmetric. No cough or gag was noted, and corneal reflexes remained absent. There were no lacerations on the tongue. The heart rhythm was tachycardic and intermittently irregular, but no murmur was noted. The skin was warm, without rashes or bruises. The remainder of the examination was unremarkable.

The blood levels of thyrotropin, free thyroxine, amylase, lipase, and carboxyhemoglobin were normal; other laboratory test results are shown in Table 1. Potassium chloride (at a dose of $40 \mathrm{mmol}$ ) was administered intravenously.

\section{Dr. Butala:}

An ECG (Figure 2A) showed sinus tachycardia with alternating left anterior fascicular block and left bundle-branch block, as well as corrected QT (QTc) prolongation.

\section{Dr. Avery:}

A chest radiograph (Figure 2B) showed clear lungs, with no evidence of pneumothorax, and a normal-sized cardiac silhouette. The endotracheal tube, pulmonary-artery catheter, and percutaneous ventricular assist device were all appropriately positioned.

\section{Dr. Butala:}

Transthoracic echocardiography (Figure 2C) showed normal left ventricular size but severe biventricular dysfunction, which was new relative to an outpatient study obtained 16 months earlier that had shown normal biventricular function. The percutaneous ventricular assist device was confirmed to be in an appropriate position, and there was no evidence of pericardial effusion (see Video 3).

\section{Dr. Henson:}

Intravenous clevidipine was administered for elevated blood pressure. Telemetric monitoring showed frequent ventricular couplets and triplets, as well as runs of nonsustained ventricular tachycardia. Amiodarone was infused intravenously. Additional arterial blood gas measurements were obtained 2 hours after the patient arrived at the ICU (Table 1), and 
the patient received $60 \mathrm{mmol}$ of intravenous potassium chloride, followed by an additional $40 \mathrm{mmol}$ of intravenous potassium chloride 2 hours later.

\section{Dr. Butala:}

A repeat ECG (Figure 2D) showed sinus tachycardia with a normal QRS duration, ventricular ectopic beat, nonspecific ST-segment and T-wave abnormalities, U waves, and QTc prolongation.

\section{Dr. Henson:}

Four hours later, an additional $40 \mathrm{mmol}$ of intravenous potassium chloride was administered after more test results were received. The patient's family provided additional history, and a diagnosis was made.

\section{Differential Diagnosis}

\section{Dr. Elazer R. Edelman:}

This 54-year-old man presents with multiorgan failure, profound metabolic derangements, and marked hypokalemia after cardiac arrest associated with ventricular fibrillation. Faced with such clinical complexity, I will focus first on the processes that govern potassium regulation and homeostasis, since they are essential for understanding and connecting the observed metabolic, renal, vascular, and cardiac conduction defects.

\section{POTASSIUM REGULATION}

The blood potassium level is the product of ingestion, internal recirculation, and elimination in the gastrointestinal and renal systems. Hypokalemia may arise from starvation or anorexia, drivers of internal recirculation (including shifts in acid-base status, as well as ion balance and internalization), and gastrointestinal or renal loss of potassium. Gastrointestinal loss of potassium can be ruled out in this case, since there is no history of vomiting, diarrhea, use of a nasogastric tube, or previous ureterosigmoidostomy. The most likely cause of this patient's hypokalemia is renal loss of potassium resulting from mineralocorticoid excess, rather than from renal tubular acidosis or medications such as diuretic agents or amphotericin.

\section{MINERALOCORTICOID EXCESS}

In the physiologic state, the ligands aldosterone and cortisol bind to the mineralocorticoid receptor and together link the powerful regulators of ion, salt, and water balance in the cortical collecting duct of the kidney with pressure, volume, and vasomotion in the cardiovascular system. There are multiple means by which this system can go awry at the ligand or receptor level (or both), resulting in primary or secondary causes of hyperaldosteronism or corticosteroid excess, as well as causes related to an excess or paucity of renin.

In this patient, we can rule out hyperreninemic hyperaldosteronism (ligand overstimulation), given that there is no evidence of renin-secreting tumors, renal-artery stenosis, decreased 
volume or chronic heart failure, edema or ascites, or syndromic elements that may affect the receptor. Similarly, there is no evidence of excess aldosterone with hyporeninism (ligand overproduction), which can occur with adrenal hyperplasia or in the context of adenomatous or cancerous growth of aldosterone-secreting cells of the adrenal cortex (Conn's syndrome). In addition, there is no evidence of adrenal medullary or pituitary tumors that can generate an excess of corticosteroids.

I suspect that the physiologic mechanism that is causing this patient's hypokalemia is most likely from mineralocorticoid or glucocorticoid excess stimulated by an exogenous compound (such as a medication or food product) or endogenous agents secreted by pituitary, adrenal, or ectopic tumors. Many of this patient's abnormal laboratory values, such as the elevations in hematopoietic cell lines, could be ascribed to the effect of a corticosteroid. Historically, the cardiac glycoside digitalis has been prescribed to treat heart failure and arrhythmias. If this patient, who had malnutrition, renal failure, and metabolic derangements, was taking digitalis products, the resulting toxic effects would be high on my differential diagnosis. Today, digitalis compounds are rarely prescribed, and they were not present in this patient. Diuretic or laxative use and abuse may cause some elements of this patient's presentation, as could a drug such as abiraterone or a substance such as grapefruit juice, but none of these are reported in the case history.

\section{ACQUIRED APPARENT MINERALOCORTICOID EXCESS}

Apparent mineralocorticoid excess-like syndromes can mimic the effects of cortisol overabundance. Cortisol and aldosterone have similar binding affinities for the mineralocorticoid receptor, but the enzyme 11 $\beta$-hydroxysteroid dehydrogenase type 2 (11ßHSD2) converts cortisol to cortisone, thereby preventing cortisol from binding to and activating the receptor. If this enzyme is blocked or inhibited, cortisol can activate the receptor, which would stimulate potassium wasting, sodium retention, hypertension, and metabolic alkalosis. Rhabdomyolysis and renal failure, both features of this patient's presentation, could occur, resulting in an increased likelihood of ventricular irritability and arrhythmias. Such enzymatic defects can be a manifestation of a genetic disorder such as an autosomal recessively inherited mutation of $H S D 11 B 2$, which encodes the kidney isozyme of $11 \beta \mathrm{HSD} 2$. Patients with this mutation usually present at a young age with severe hypertension and end-organ manifestations, such as left ventricular hypertrophy and retinal, renal, and neurologic vascular changes, along with growth retardation and failure to thrive. This patient is middle-aged and has a relatively unremarkable medical history; hence, the presence of an acquired enzymatic disorder is more likely than an underlying undiagnosed genetic abnormality.

The notable aspect of each of the increasing number of compounds that can induce apparent mineralocorticoid excess (cortisol, digitalis, glycyrrhetinic acid, and abiraterone) is that they are structurally similar to one another and to aldosterone (Figure 3). Thus, it is not difficult to imagine that each of these compounds could cause an acquired apparent mineralocorticoid excess. In fact, this chemical similarity could well be used to predict the potential of emerging compounds to induce apparent mineralocorticoid excess. 


\section{LICORICE AND GLYCYRRHETINIC ACID}

We are told that this patient has a poor diet and eats a lot of candy. Could his

illness be related to candy consumption? Licorice has long been used as a medication and a food sweetener, albeit not without side effects. In 1946, the Dutch physicianscientist Revers reported that the active ingredient (succus liquiritiae, or "licorice juice") of a proprietary preparation relieved gastrointestinal ulcer disease. ${ }^{1}$ However, when the preparation was modified, the beneficial effect was accompanied by edema, headache, and dyspnea on exertion. ${ }^{2}$ In subsequent studies, researchers isolated glycyrrhizic acid from licorice preparations and initially surmised a direct effect on the mineralocorticoid receptor; subsequently, they determined that there was an indirect effect through inhibition of $11 \beta \mathrm{HSD} 2 .^{3}$ The resultant unimpeded presence of cortisol can cause hypertension, hypokalemia, metabolic alkalosis, fatal arrhythmias, and renal failure - the constellation of signs and symptoms seen in this patient, many of which were observed by Revers.

In short, water and sodium retention and potassium wasting arise from toxic effects of ATPase activity in the collecting duct, which also increases blood pressure through expansion of blood volume. Counterregulatory measures reduce renal renin and angiotensin II secretion and aldosterone production in the adrenal cortex. However, increasing cortisol levels and unrestricted activation of the mineralocorticoid receptor by cortisol can raise the level of aldosterone (pseudohyperaldosteronism), which can then elicit a cascade of further elevation in blood volume and cardiac preload. In addition, glycyrrhetinic acid itself can inhibit reduction of aldosterone by hepatic enzymes ( $5 \beta$-reductase and $3 \beta$-hydroxysteroid dehydrogenase), thereby further increasing circulating aldosterone levels. These competing phenomena have variable effects on aldosterone levels. Elevated vasomotor tone is maintained as nitric oxide bioavailability is reduced and vascular endothelin is increased, enhancing contractile responses to pressor hormones (Figure 4). ${ }^{4}$

Effects on cardiac conduction are similar to other inhibitors of sodium-potassium ATPase. ${ }^{5}$ Earlier reference to the plant-derived cardiac glycoside digitalis is not tangential. Although glycyrrhetinic acid and digitalis act at different sites, both affect ionic balance in the control of action potential-driven impulse generation and conduction. Given that the root-derived glycoside glycyrrhetinic acid competitively inhibits ATP binding to the enzyme and digitalis preparations inhibit the sodium pump by binding to its extracellular potassium binding site, ${ }^{6}$ there is the potential for similar effects on cardiac conduction. This patient's ECG abnormalities (in addition to those associated with hypokalemia) may well mimic the classic toxic effects seen with digitalis, with regularization of atrial fibrillation and alternating fascicular block.

Some of the traditionally prescribed initial pharmacologic interventions used for resuscitations that were also used in this patient may have aggravated his condition. The use of catecholamines, such as epinephrine and norepinephrine, and vasopressin could have exacerbated the effects of 11ßHSD2 blockade. The conversion to mechanical resuscitation allowed this patient to avoid possible metabolic side effects of potent inotropes and vasoconstrictors while providing tandem and synchronized cardiac support. Intravenous calcium chloride, as well as dextrose and insulin, could have made 
this patient's hypokalemia worse and led to his transient hypercalcemia, which, in a patient with a disordered metabolic presentation that was complicated by chronic malnutrition, hypoalbuminemia, and hyperglycemia, exacerbated the overall effect. Persistent hypercalcemia was not observed in this patient, and indeed, the level of ionized calcium was normal, even with markedly elevated levels of calcium and phosphorus. The patient's initial potassium level of $3.5 \mathrm{mmol}$ per liter was probably spurious, given that the sample had hemolyzed; the level was most likely lower (as low as $1.6 \mathrm{mmol}$ per liter). Later, when hypertension was observed, the patient was treated with a calcium-channel blocker - a drug class that traditionally has been viewed as having minimal effects on the blood potassium level and in fact may raise levels and drive the ion intracellularly. Therapeutic temperature management, which was not implemented in this patient, might well have driven potassium levels even lower.

A precise diagnosis of hypokalemia due to licorice consumption is often made by association. It can be supported by documentation of inappropriately elevated urine potassium levels, with a transtubular potassium gradient above 7 , coincident with low plasma renin levels. Aldosterone and angiotensin II levels are often low with licorice consumption but can vary widely and are not discriminatory. A 24-hour urine collection may be necessary to rule out underlying tubular dysfunction, as well as a decreased urinary free cortisone level and an increased ratio of urinary free cortisol to urinary free cortisone. In contrast, primary hyperaldosteronism is associated with an abnormally increased aldosterone-to-renin ratio, and secondary hyperaldosteronism with a decreased or normal ratio but with a high plasma renin level. The effects of licorice on 11ßHSD2 activity are similar to those seen in children with the syndrome of apparent mineralocorticoid excess. However, the elevated urinary ratio of $5 \beta$-tetrahydrocortisol to $5 a$-tetrahydrocortisol that occurs with licorice ingestion is unlike the findings in such children, in whom 5a-reductase activity is increased relative to $5 \beta$-reductase activity. ${ }^{7}$ Assays to identify the levels of glycoside and aglycone in plasma and urine are available and could be of diagnostic value in this case.

Unlike Liddle's syndrome, apparent mineralocorticoid excess, and glucocorticoidremediable aldosteronism - all of which are not correctable and require lifelong potassium supplementation and potassium-sparing diuretics - the manifestations of licorice excess are eventually reversible with cessation of ingestion. Glycyrrhetinic acid has a long half-life, a large volume of distribution, and extensive enterohepatic recirculation, and hypokalemia may take 1 to 2 weeks to resolve. Normalization of the renin-aldosterone axis and blood pressure can take up to several months. As such, the devastating consequences after cardiac arrest will probably dominate long after the candy is cleared.

\section{Dr. Elazer R. Edelman's Diagnosis}

Metabolic, renal, vascular, and cardiac toxic effects from apparent mineralocorticoid excess due to licorice consumption. 


\section{Pathological Discussion}

\section{Dr. Anand S. Dighe:}

In a random urine sample, the sodium level was $119 \mathrm{mmol}$ per liter, the potassium level 13.8 mmol per liter, the chloride level $98 \mathrm{mmol}$ per liter, and the creatinine level $0.06 \mathrm{~g}$ per liter. The elevated ratio of potassium to creatinine in the urine $(230 \mathrm{mmol}$ of potassium per gram of creatinine) was suggestive of renal potassium loss, since a ratio greater than $13 \mathrm{mmol}$ of potassium per gram of creatinine is associated with renal potassium wasting. It should be noted that the ratio of potassium to creatinine may not be reliable in the context of acute kidney injury. ${ }^{8}$ Certain types of diuretics can cause or exacerbate renal potassium losses. However, an assay that evaluated the presence of several common loop and thiazide diuretics in the urine was negative.

Measurement of plasma renin activity and the serum aldosterone level was performed to assess for the presence of mineralocorticoid excess. Plasma renin activity was evaluated with the use of an assay that measures the ability of endogenous renin to act on endogenous angiotensinogen in vitro to form angiotensin I. The plasma renin activity was undetectable $(<0.4 \mathrm{ng}$ per milliliter per hour; reference range, $₫ 0.6$ to 3.0). The serum aldosterone level, measured by means of high-performance liquid chromatography and mass spectrometry, was also below the level of detection $(<4.0 \mathrm{ng}$ per deciliter; reference range, $\boldsymbol{\Omega} 1)$. Taken together, the low aldosterone level and the low renin activity provide no evidence of either primary hyperaldosteronism (in which the aldosterone level is elevated and the renin level is low) or secondary hyperaldosteronism (in which both the aldosterone level and the renin level are elevated).

In a random urine sample, the level of urinary free cortisol was highly elevated at 1857 $\mu \mathrm{g}$ per gram of creatinine (reference range, 1 to 119). Measurement of urine cortisol and cortisone levels may assist in the diagnosis of inherited or acquired abnormalities of $11 \beta \mathrm{HSD} 2$. The ratio of urinary cortisol to cortisone would be expected to be elevated in the case of deficiency or inhibition (e.g., by licorice metabolites) of 11ßHSD2 activity, which would reduce the conversion of cortisol to cortisone. It is recommended that the assessment of urine cortisol and cortisone levels be based on a 24-hour urine specimen owing to the pulsatile nature of cortisol secretion. The ability to measure glycyrrhetinic acid metabolites in both the blood and urine has been reported, and such testing may be available at specialized laboratories. ${ }^{9}$ Glycyrrhetinic acid metabolite testing was not performed in this case.

\section{Pathological Diagnosis}

Pseudohyperaldosteronism suggestive of excessive licorice consumption.

\section{Clinical Impression and Management}

\section{Dr. Andrew L. Lundquist:}

The causes of renal potassium loss can be divided into two categories: those typically associated with low or normal blood pressure, such as renal tubular acidosis, use of 
diuretics, magnesium deficiency, Bartter's syndrome, and Gitelman's syndrome, and those associated with hypertension, including renal artery stenosis, hyperaldosteronism, and apparent mineralocorticoid excess. ${ }^{10}$ This patient's baseline blood pressure was unknown (given that he was in shock at presentation), his diuretic screen was negative, and his baseline magnesium level was normal. It is notable that his plasma renin and serum aldosterone levels were both low, consistent with a disorder that is associated with a mineralocorticoid other than aldosterone, such as Cushing's syndrome or ectopic corticotropin, Liddle's syndrome, or apparent mineralocorticoid excess due to $11 \beta \mathrm{HSD} 2$ deficiency or licorice consumption. Although this patient's elevated free cortisol level in the spot urine sample could be consistent with several of these possibilities, his age at presentation and his previously normal potassium levels do not support an inherited syndrome. Further investigation revealed a recent change to a licorice-containing candy as the likely cause of his hypokalemia. ${ }^{7,11}$

Persistent hypokalemia results in hyperpolarization of cell membranes and muscle weakness. Extremely low blood potassium levels ( $<2.5 \mathrm{mmol}$ per liter) can lead to rhabdomyolysis, arrhythmias, and respiratory paralysis. With a blood potassium level of $2.0 \mathrm{mmol}$ per liter, this patient's total body potassium deficit is approximately 400 to 600 $\mathrm{mmol}^{10}$; thus, extensive repletion is warranted. Options for repletion include oral potassium chloride at a dose of up to $150 \mathrm{mmol}$ per day, intravenous potassium chloride (with a peripheral intravenous potassium chloride concentration limited to $40 \mathrm{mmol}$ per liter to prevent phlebitis), or central intravenous potassium chloride, if higher concentrations are necessary. Previous studies suggest a maximal potassium repletion rate of $20 \mathrm{mmol}$ per hour, ${ }^{1}$ although this patient received emergency treatment with more than $400 \mathrm{mmol}$ of potassium chloride over the course of 12 hours. In such cases, it is necessary to monitor the patient with continuous telemetry and to measure the potassium level frequently to avoid overcorrection. Additional management includes cessation of licorice consumption, ongoing potassium repletion (with consideration of both the deficit and the daily potassium need), and the use of potassium-sparing diuretics if deemed necessary, since the effects of licorice can persist for weeks after cessation.

\section{Follow-up \\ Dr. Butala:}

During the first 12 hours of this patient's hospitalization, $420 \mathrm{mmol}$ of potassium repletion was required to achieve a potassium level of $4.3 \mathrm{mmol}$ per liter. Several hours after his arrival at the cardiac ICU, his blood pressure became more labile and he received multiple vasopressors. He was evaluated for extracorporeal membrane oxygenation but was deemed not to be a candidate owing to his poor neurologic prognosis. He began to have oliguria, which progressed to anuria. The goals of care were discussed with his family, who declined renal replacement therapy, and the patient was subsequently transitioned to comfort measures only. He died comfortably with his family at his bedside, 32 hours after presentation. On the basis of additional history obtained from his family, the patient was eating one or two large packages of soft candy daily. Three weeks before presentation, he 
had switched from eating fruit-flavored soft candy to eating licorice-flavored soft candy that contained glycyrrhizic acid, which is converted to glycyrrhetinic acid after it is consumed.

\section{Final Diagnosis}

Pseudohyperaldosteronism suggestive of excessive licorice consumption complicated by cardiac arrest associated with ventricular fibrillation.

\section{Supplementary Material}

Refer to Web version on PubMed Central for supplementary material.

\section{Acknowledgments}

We thank Dr. Christopher H. Newton-Cheh for his assistance with the case presentation and preparation of an earlier version of the manuscript.

\section{References}

1. Revers FE. Heeft succus liquiritiae een genezende werking op ce maagzweer? Ned Tijdschr Geneeskd 1946;90:135-137. [PubMed: 20291620]

2. Revers FE. De behandling van ulcus ventriculi en ulcus duodeni met succus liquiritiae. Ned Tijdschr Geneeskd 1948;92:2968-2973. [PubMed: 18894329]

3. Molhuysen JA, Gerbrandy J, de Vries LA, et al. A liquorice extract with deoxycortone-like action. Lancet 1950;2:381-386. [PubMed: 14785168]

4. Deutch MR, Grimm D, Wehland M, Infanger M, Krüger M. Bioactive candy: effects of licorice on the cardiovascular system. Foods 2019;8:495-495.

5. Garcia A, Rasmussen HH, Apell H-J, Clarke RJ. Kinetic comparisons of heart and kidney $\mathrm{Na+,K(+)-ATPases.} \mathrm{Biophys} \mathrm{J} \mathrm{2012;103:677-688.} \mathrm{[PubMed:} \mathrm{22947929]}$

6. Matchkov VV, Gustafsson H, Rahman A, et al. Interaction between $\mathrm{Na}+\mathrm{K}+-$ pump and $\mathrm{Na}+/$ Ca2+-exchanger modulates intercellular communication. Circ Res 2007;100:1026-1035. [PubMed: 17347477]

7. Farese RV Jr, Biglieri EG, Shackleton CH, Irony I, Gomez-Fontes R. Licorice-induced hypermineralocorticoidism. N Engl J Med 1991;325:1223-1227. [PubMed: 1922210]

8. Kamel KS, Ethier JH, Richardson RMA, Bear RA, Halperin ML. Urine electrolytes and osmolality: when and how to use them. Am J Nephrol 1990;10:89-102. [PubMed: 2190469]

9. Kato H, Kanaoka M, Yano S, Kobayashi M. 3-Monoglucuronyl-glycyrrhetinic acid is a major metabolite that causes licorice-induced pseudoaldosteronism. J Clin Endocrinol Metab 1995;80:1929-1933. [PubMed: 7775643]

10. Palmer BF, Clegg DJ. Physiology and pathophysiology of potassium homeostasis: core curriculum 2019. Am J Kidney Dis 2019;74:682-695. [PubMed: 31227226]

11. Mumford E, Unwin RJ, Walsh SB. Liquorice, Liddle, Bartter or Gitelman - how to differentiate? Nephrol Dial Transplant 2019;34:38-39. [PubMed: 29982819] 

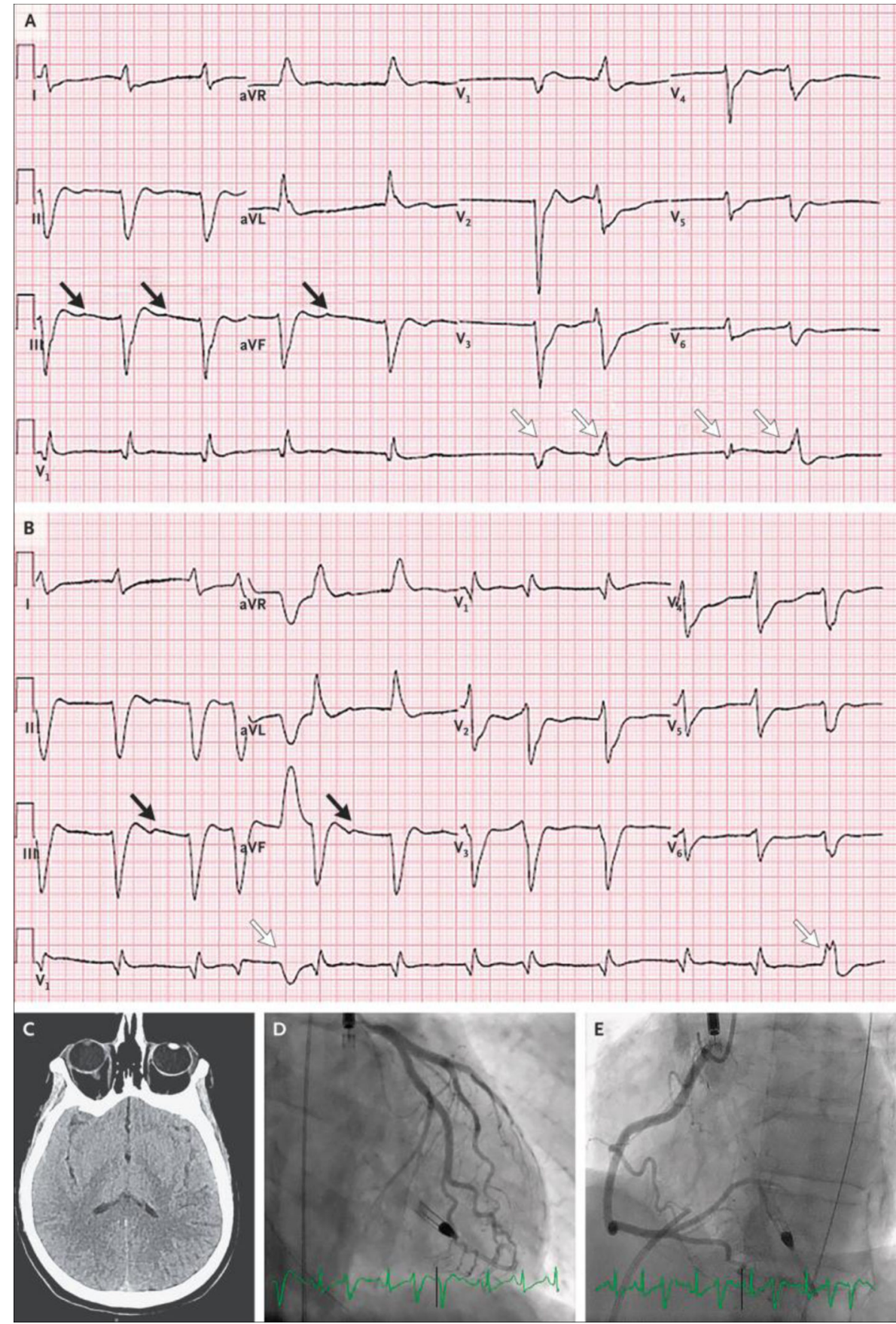

Figure 1.

Initial ECGs, CT Scan of the Head, and Cardiac Catheterization Studies. Electrocardiograms (ECGs) obtained on presentation (Panel A) and after the return of spontaneous circulation (Panel B) show uncertain atrial activity; a regular accelerated idioventricular rhythm at a rate of 70 beats per minute, with a very wide QRS complex and multifocal premature ventricular contractions (white arrows); possible elevations of the ST segment in leads aVR, aVL, and $\mathrm{V}_{1}$; and the presence of $\mathrm{U}$ waves (black arrows). An axial computed tomographic (CT) image of the head (Panel C), obtained without the administration of contrast material, was 
normal, without evidence of infarct, intracranial hemorrhage, or mass lesions. Images from a left coronary angiogram (Panel D) and a right coronary angiogram (Panel E) show only minimal luminal irregularities. 

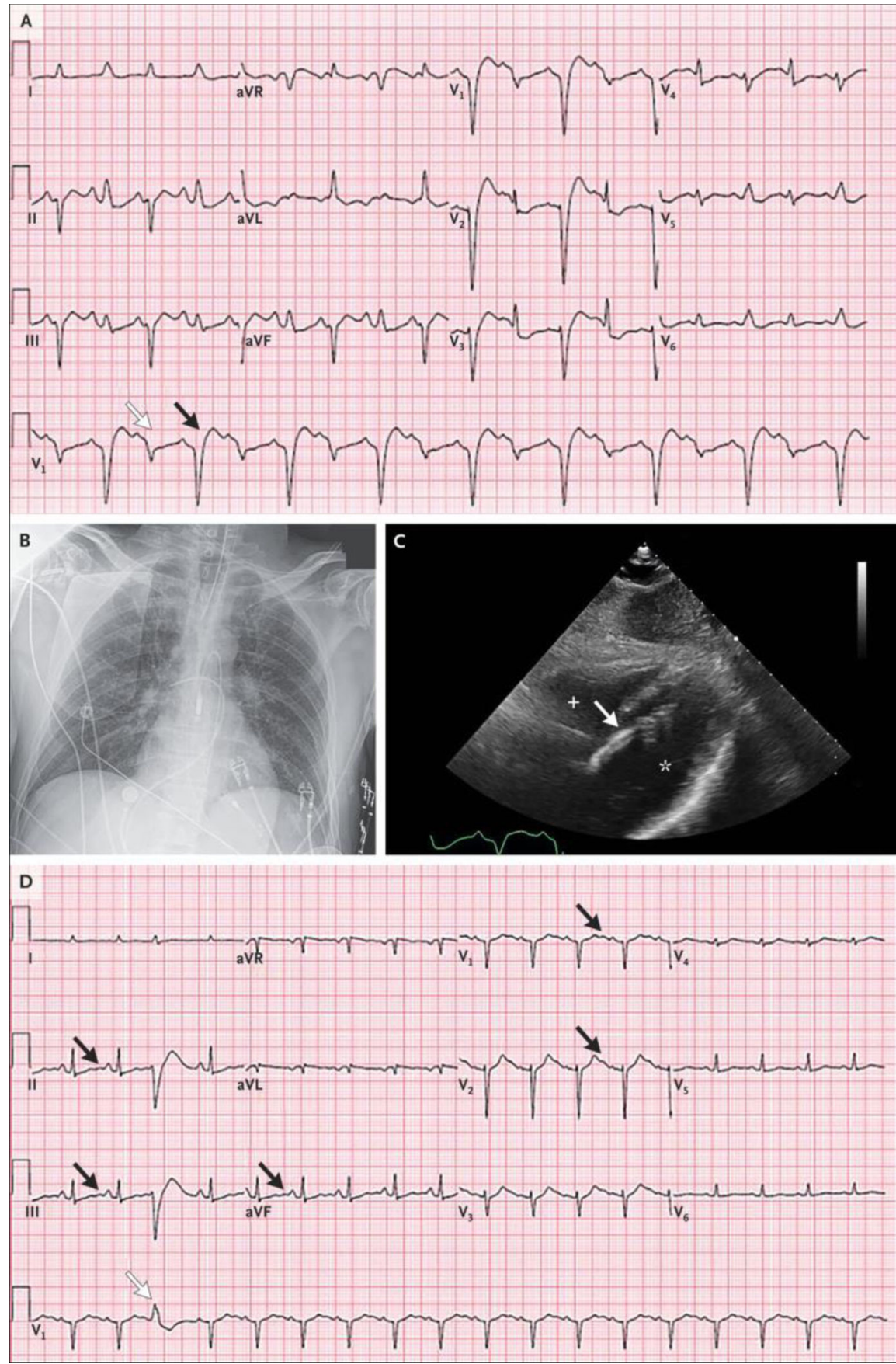

Figure 2.

Additional Cardiac and Imaging Studies. An ECG obtained on the patient's arrival at the cardiac intensive care unit (ICU) (Panel A) shows sinus tachycardia with alternating left anterior fascicular block (white arrow) and left bundle-branch block (black arrow), as well as corrected QT (QTc) prolongation. A portable chest radiograph (Panel B) shows appropriate positioning of the endotracheal tube, the pulmonary-artery catheter, and the percutaneous ventricular assist device. The lungs are clear, and the cardiac silhouette is normal in size. A transthoracic echocardiogram (subcostal view) (Panel C) shows normal left ventricular 
size (asterisk) but biventricular dysfunction. The plus sign denotes the right ventricle. The percutaneous ventricular assist device (white arrow) is in an appropriate position, and there is no evidence of pericardial effusion. A repeat ECG obtained in the cardiac ICU (Panel D) shows sinus tachycardia with a normal QRS duration, ventricular ectopic beat (white arrow), nonspecific ST-segment and T-wave abnormalities, U waves (black arrows), and QTc prolongation. 
Aldosterone
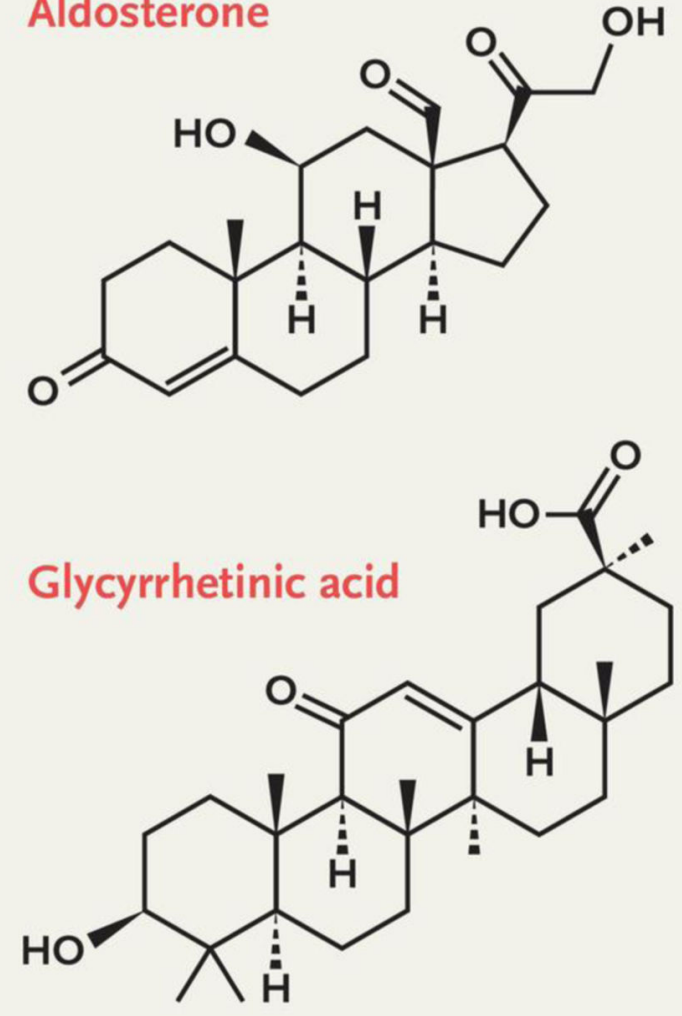
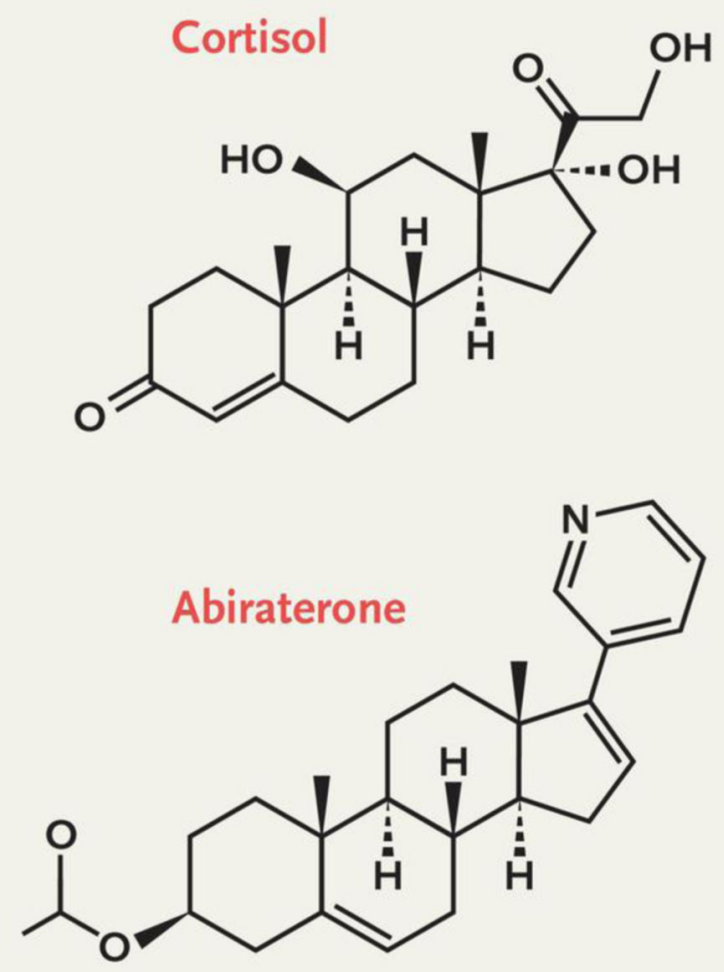

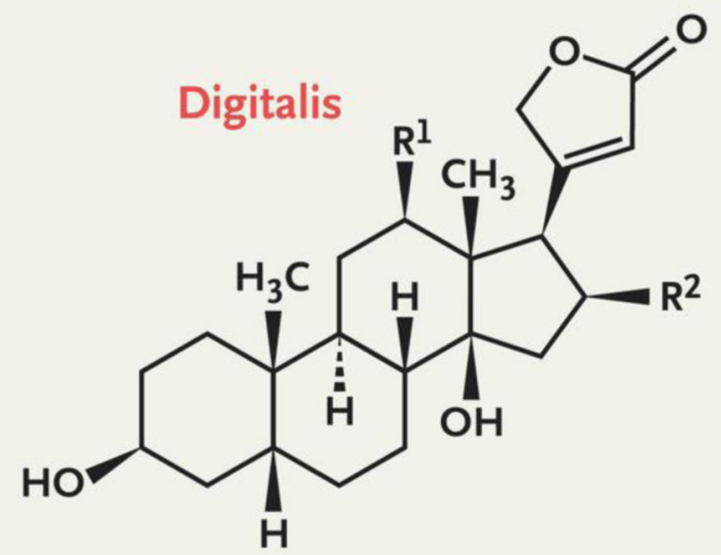

Figure 3.

Chemical Similarities of Drugs That Can Induce Apparent Mineralocorticoid Excess. The notable aspect of each of the increasing number of compounds that can induce apparent mineralocorticoid excess (cortisol, digitalis, glycyrrhetinic acid, and abiraterone) is that they are chemically similar to one another and to aldosterone. Depicted here are the aglycone components of these compounds, which are all congeners of the 21-carbon sterol. Thus, it is not difficult to imagine that each of these compounds could create an acquired apparent mineralocorticoid excess by binding to and activating the mineralocorticoid receptor and 
other critical receptors in the pathway. In fact, this chemical similarity could well be used to predict the potential of emerging compounds to induce apparent mineralocorticoid excess. $\mathrm{R}^{1}$ and $\mathrm{R}^{2}$ on the digitalis structure reflect the substitution groups that distinguish individual cardiac glycosides. 


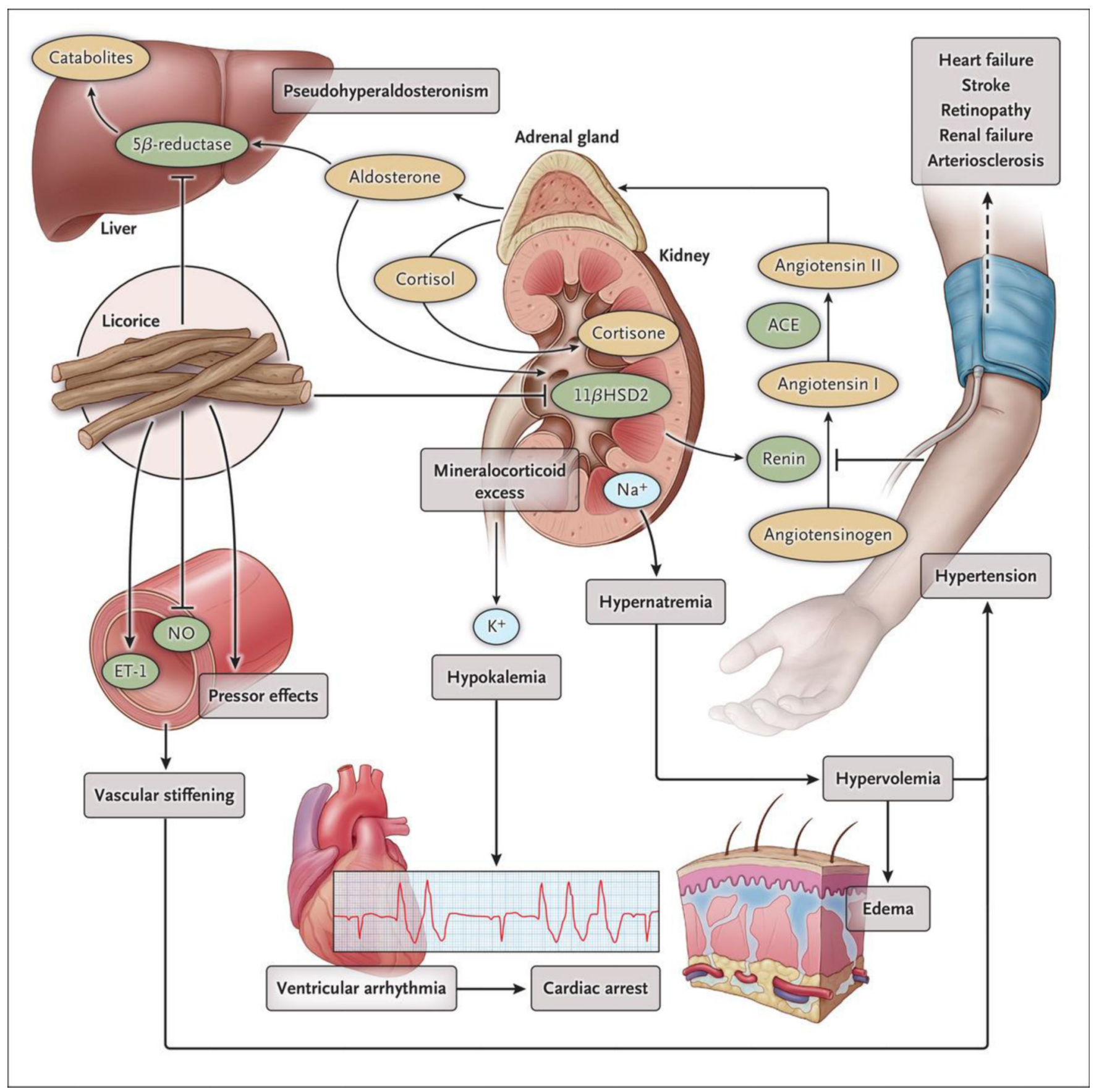

Figure 4.

Physiological Effects of Glycyrrhetinic Acid. Glycyrrhetinic acid was first surmised to have a direct effect on the mineralocorticoid receptor but was subsequently found to have an indirect effect through inhibition of $11 \beta$-hydroxysteroid dehydrogenase type $2(11 \beta \mathrm{HSD} 2)^{3}$

The resultant unimpeded presence of cortisol can induce hypertension, hypokalemia, metabolic alkalosis, fatal arrhythmias, and renal failure - the constellation of effects seen in this patient. Water and sodium retention and potassium wasting arise from toxic effects of ATPase activity in the collecting duct, further increasing blood pressure through expansion 
of blood volume. Counterregulatory measures reduce renal renin and angiotensin II secretion and aldosterone production in the adrenal cortex. However, increasing cortisol levels and unrestricted activation of the mineralocorticoid receptor can raise the level of aldosterone (pseudohyperaldosteronism), eliciting a cascade of further elevations in blood volume and cardiac preload. Glycyrrhetinic acid can also inhibit metabolism of aldosterone by hepatic enzymes ( $5 \beta$-reductase and $3 \beta$-hydroxysteroid dehydrogenase), thereby further increasing circulating aldosterone levels. Elevated vasomotor tone is maintained as nitric oxide (NO) bioavailability is reduced and vascular endothelin (ET-1) is increased, enhancing contractile responses to pressor hormones. This figure is adapted from Deutch et al. ${ }^{4}$ ACE denotes angiotensin-converting enzyme. 
Video 1. 
Video 2.

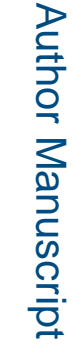

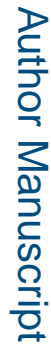

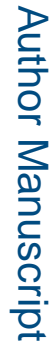

NEngl J Med. Author manuscript; available in PMC 2021 November 04. 
Video 3.

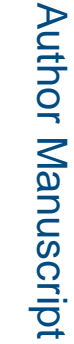

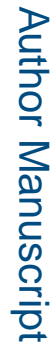

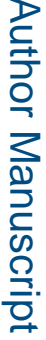

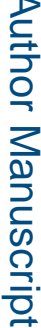

NEngl J Med. Author manuscript; available in PMC 2021 November 04. 
Table 1.

Laboratory Data.

\begin{tabular}{|c|c|c|c|c|c|c|}
\hline Variable & $\begin{array}{c}\text { Reference Range, } \\
\text { Adults }{ }^{\dagger}\end{array}$ & $\begin{array}{c}\text { On } \\
\text { Arrival, } \\
\text { This } \\
\text { Hospital }\end{array}$ & $\begin{array}{c}\text { At Time of } \\
\text { Cardiac } \\
\text { Catheterization, } \\
\text { This Hospital }\end{array}$ & $\begin{array}{c}\text { On Arrival } \\
\text { at Cardiac } \\
\text { ICU,3 Hr } \\
\text { after } \\
\text { Arrival, } \\
\text { This } \\
\text { Hospital }\end{array}$ & $\begin{array}{c}2 \text { Hr after } \\
\text { Arrival } 4 \\
\text { Hr after } \\
\text { Arrival at } \\
\text { Cardiac } \\
\text { ICU at } \\
\text { Cardiac } \\
\text { ICU }\end{array}$ & $\begin{array}{c}8 \text { Hr after } \\
\text { Arrival at } \\
\text { Cardiac } \\
\text { ICU }\end{array}$ \\
\hline \multicolumn{7}{|l|}{ Blood } \\
\hline Sodium (mmol/liter) & $135-145$ & 149 & 149 & 146 & 147 & 150 \\
\hline Potassium (mmol/liter) & $3.4-5.0$ & $3.5^{*}$ & 2.0 & 2.0 & 3.1 & 3.1 \\
\hline Chloride (mmol/liter) & $98-108$ & 96 & 96 & 96 & 100 & 102 \\
\hline Carbon dioxide (mmol/liter) & $23-32$ & 6 & 33 & 30 & 19 & 20 \\
\hline Urea nitrogen (mg/dl) & $8-25$ & 13 & 14 & 15 & 18 & 18 \\
\hline Plasma creatinine $(\mathrm{mg} / \mathrm{dl})$ & $0.60-1.50$ & 1.79 & 1.78 & 1.85 & 2.30 & 2.45 \\
\hline Glucose (mg/dl) & $70-110$ & 319 & 262 & 211 & 220 & 58 \\
\hline Lactate (mmol/liter) & $0.5-2.2$ & 26.3 & 10.6 & 8.0 & & 13.6 \\
\hline Hemoglobin $(\mathrm{g} / \mathrm{dl})$ & $12.0-16.0$ & 13.8 & & 13.4 & 13.7 & \\
\hline Hematocrit (\%) & $36.0-46.0$ & 44.6 & & 39.6 & 40.5 & \\
\hline White-cell count (per $\mu \mathrm{l}$ ) & $4500-11,000$ & 16.88 & & 16.98 & 32.53 & \\
\hline Platelet count (per $\mu \mathrm{l})$ & $150,000-400,000$ & 178,000 & & 251,000 & 257,000 & \\
\hline Calcium (mg/dl) & $8.5-10.5$ & 15.6 & & 9.2 & 8.6 & 8.5 \\
\hline Ionized calcium (mmol/liter) & $1.14-1.30$ & 1.26 & & 1.17 & & 1.10 \\
\hline Phosphorus (mg/dl) & $2.6-4.5$ & 10.7 & & 4.6 & & \\
\hline Total protein $(\mathrm{g} / \mathrm{dl})$ & $6.0-8.3$ & & & & & \\
\hline Albumin (g/dl) & $3.3-5.0$ & 2.9 & & 2.6 & & 2.2 \\
\hline Lactate dehydrogenase (U/liter) & $111-210$ & & & 744 & 1569 & \\
\hline $\begin{array}{l}\text { Alanine aminotransferase (U/ } \\
\text { liter) }\end{array}$ & $10-55$ & 74 & & 83 & & 248 \\
\hline $\begin{array}{l}\text { Aspartate aminotransferase (U/ } \\
\text { liter) }\end{array}$ & $10-40$ & 102 & & 176 & & 780 \\
\hline $\begin{array}{l}\text { N-terminal pro-B-type } \\
\text { natriuretic peptide }(\mathrm{pg} / \mathrm{ml})\end{array}$ & $<900$ & 1942 & & & & \\
\hline $\begin{array}{l}\text { High-sensitivity troponin } \mathrm{T} \text { (ng/ } \\
\text { liter) }\end{array}$ & $0-14$ & & 1614 & & & 14,304 \\
\hline Creatine kinase (U/liter) & $60-400$ & & 2473 & & 9504 & \\
\hline Creatine kinase MB (ng/ml) & $0-6.9$ & & 149.7 & & 338.0 & \\
\hline \multicolumn{7}{|l|}{ Venous blood gases } \\
\hline Fraction of inspired oxygen & & 1.0 & & & & \\
\hline $\mathrm{pH}$ & $7.30-7.40$ & $<6.77$ & & & & \\
\hline $\mathrm{PcO}_{2}(\mathrm{~mm} \mathrm{Hg})$ & $38-50$ & $>152$ & & & & \\
\hline $\mathrm{Po}_{2}(\mathrm{~mm} \mathrm{Hg})$ & $35-50$ & 43 & & & & \\
\hline \multicolumn{7}{|l|}{ Arterial blood gases } \\
\hline Fraction of inspired oxygen & & & 1.0 & 0.50 & $0.500 . S 0$ & 0.50 \\
\hline
\end{tabular}




\begin{tabular}{|c|c|c|c|c|c|c|}
\hline Variable & $\begin{array}{c}\text { Reference Range, } \\
\text { Adults }^{\dagger}\end{array}$ & $\begin{array}{c}\text { On } \\
\text { Arrival, } \\
\text { This } \\
\text { Hospital }\end{array}$ & $\begin{array}{c}\text { At Time of } \\
\text { Cardiac } \\
\text { Catheterization, } \\
\text { This Hospital }\end{array}$ & $\begin{array}{c}\text { On Arrival } \\
\text { at Cardiac } \\
\text { ICU, } 3 \mathrm{Hr} \\
\text { after } \\
\text { Arrival, } \\
\text { This } \\
\text { Hospital }\end{array}$ & $\begin{array}{c}2 \text { Hr after } \\
\text { Arrival } 4 \\
\text { Hr after } \\
\text { Arrival at } \\
\text { Cardiac } \\
\text { ICU at } \\
\text { Cardiac } \\
\text { ICU }\end{array}$ & $\begin{array}{c}8 \mathrm{Hr} \text { after } \\
\text { Arrival at } \\
\text { Cardiac } \\
\text { ICU }\end{array}$ \\
\hline $\mathrm{pH}$ & $7.35-7.45$ & & 7.23 & 7.36 & 7.497 .49 & 7.38 \\
\hline $\mathrm{Pco}_{2}(\mathrm{~mm} \mathrm{Hg})$ & $35-42$ & & 76 & 64 & 4543 & 35 \\
\hline $\mathrm{Po}_{2}(\mathrm{~mm} \mathrm{Hg})$ & $80-100$ & & 296 & 89 & 6676 & 171 \\
\hline $\begin{array}{l}\text { Potassium, whole blood (mmol/ } \\
\text { liter) }\end{array}$ & $3.5-5.0$ & & 1.6 & 1.7 & 1.92 .5 & 2.9 \\
\hline \multicolumn{7}{|l|}{ Urine } \\
\hline Red cells (per high-power field) & $0-2$ & $50-100$ & & & & \\
\hline $\begin{array}{l}\text { White cells (per high-power } \\
\text { field) }\end{array}$ & $<10$ & $<10$ & & & & \\
\hline Bacteria & None & $1+$ & & & & \\
\hline Toxicology tests & $\begin{array}{l}\text { Negative for 6- } \\
\text { mono-acetylmorphine, } \\
\text { amphetamines, } \\
\text { barbiturates, } \\
\text { benzodiazepines, } \\
\text { buprenorphine, } \\
\text { cannabinoids, } \\
\text { cocaine, methadone, } \\
\text { opiates, oxycodone, } \\
\text { phencyclidine }\end{array}$ & Negative & & & & \\
\hline
\end{tabular}

To convert the values for urea nitrogen to millimoles per liter, multiply by 0.357 . To convert the values for creatinine to micromoles per liter, multiply by 88.4 . To convert the values for glucose to millimoles per liter, multiply by 0.05551 . To convert the values for lactate to milligrams per deciliter, divide by 0.1110 . To convert the values for calcium to millimoles per liter, muliply by 0.250 . To convert the values for phosphorus to millimoles per liter, multiply by 0.3229 . Pco2 denotes partial pressure of carbon dioxide, and Po2 partial pressure of oxygen.

${ }^{\dagger}$ Reference values for affected by many variables, including the patient population and the laboratory methods used. The ranges used at Massachussets General Hospital are for adults who are not pregnant and do not have medical conditions that could affect the results. They may therefore not be appropriate for all patients.

The blood sample was grossly hemolyzed. 